\title{
Chapter 11 \\ Conclusion: The Need to Develop the Code of the Street into a General Approach
}

\author{
Wilhelm Heitmeyer, Sebastian Kurtenbach and Steffen Zdun
}

\subsection{Answer of the Research the Question}

A cross-cultural comparison of the single elements of the code of the street shows differences and similarities to the original theory, which will be reflected in the following chapter. The purpose is to evaluate if the code of the street is a general concept or, limited just to the US or only in part operational in all contexts. Our study started with the research question: Does the code of the street operate equally in different contexts than that of the US? The answer is no. We do see significant differences in the elements of the code of the street in the examined countries. However, the code of the street is a well-established concept used to analyze youth violence in risky neighborhoods and it is an important explanation for street violence occurring in African American neighborhoods in the US. Moreover, it has become a wellresearched theoretical explanation to understand youth violence in other contexts too, but a reflection of its limitations was still lacking. These variances of the code in different countries and neighborhoods should not be underestimated, because it limits the range of the concept as it has been formulated. The established concept of the code of the street cannot explain them.

As Anderson proposes, elements of the code hark back to the time of the Roman Empire. We are able to discuss now if there are elements that are stable across very different countries, and if so, we can propose too that over time and generation the relational circumstances are stable as well. However, one basic assumption of the street code approach did not turn up in our research. The binominal logic of "street" or "decent" families or individuals was not observable in any of the neighborhoods where we conducted our study. For example, juveniles in Dortmund or Berlin behave violently on the street but act decently in the family milieu. This ambiguity is more than just simple code-switching because decency is part of the street identity, even for highly violent individuals. The same is true for adolescents in Pakistan, in particular. However, juveniles in risky neighborhoods of South Africa were often not embedded in such tightly knit family relations in their communities, both because of broken families as well as high homicide rates. There, male juveniles need to develop another 
kind of street code and its elements need to sample together but differently from other contexts.

\subsection{Similarities to the Code: Evidence of Cross-Cultural Comparison}

In our intensive study, we found three striking similarities between the assumptions of the code, as Anderson proposed it, and our findings. The first, and for the entire concept the most important element, is respect. This is the symbolic currency of the street, for male juveniles in particular, and their campaign for respect is part of their daily routines. Therefore, many different strategies are developed by young men in each of the settings under investigation, which range from being a good friend and a peaceful person to "gangster-style" behavior. However, one important expectation of the similarity of our findings with those of Anderson needs to be mentioned. The role of violence in the campaign for respect is not uniform among all countries and neighborhoods. In the neighborhoods researched in South Africa, the assumption is very similar to how Anderson described the pathways of early 1990s Germantown, but it is not true for Germany, as shown in Chap. 9. Violence is a reaction to a perceived threat or as a way of self-defense; it is not a means to ensure that certain things will be done. Regarding the issue of respect, the level of violence is unclear. The ability to fight is connected to respect, but not the aggressive behavior itself. Dissimilar to Anderson's description, the ability to "freak out" does not build up a respectful reputation. Maybe what Anderson describes is true for all socially segregated neighborhoods in American metropoles, independent of the ethnic or religious groups who live there, however, the way respect is developed and maintained is different in other countries. These exceptions remind us that respect needs to be analyzed in the context where it is perceived as such.

The second similarity of the street code approach, as outlined by Anderson, and our cross-cultural findings is the perception of space-most importantly, the neighborhood. The social and spatial environment of male juveniles is perceived as a threat. Following this path, the development of code, as a coping strategy to handle the challenging environment, is rational. Not completely explained, however, is the mechanism as to how the threatening image of the space is built up. Part of it is the behavior of peers or people in the same age group. Their (deviant) behavior places juveniles in the position to react, which means that they must build up a violent reputation to stay safe. This is the purpose of their performance on the street towards peers but ignoring the fact that such behavior is threatened in return. This paradox of threatening behavior as a reaction towards the threat of others, causes the construction of a street code. Here, the risky neighborhood evolves its effect because it is not possible to refer to collective and generally accepted norms. However, neither in our study nor in Anderson's approach the interactive effects between different age groups, ethnic groups, public or private agents towards the perception of space 
are clearly explained. In our study, we focused on the concept of the code of the street in particular, but it is necessary to keep in mind that other elements are part of the code too, which are not connected to violence and were beyond the scope of this analysis. Thus, we need a broader understanding of the street code in further studies. The below discussion about street culture could provide a helpful approach to understanding this complex and dynamic field (Ross 2018). This discussion particularly addresses the fact that street culture goes far beyond engaging in violence, which is just one extreme option of showing off in public. Many daily interactions are based on the street habitus - streetwise behavior, even aggressive but non-violent displays of masculinity-however, they do not go further. In other words, a lot of street cultural behavior is more about a tough appearance in public than about actual violent behavior. ${ }^{1}$

Third, the lengthy description of informal rules on the street code approach is very fruitful for understanding youth violence in risky neighborhoods. This street wisdom, as a fluid knowledge about how to stay safe in violent situations without losing street reputation, helps to find the individual's place within the social hierarchy and network of the street. Outside of the code of the street debate, this has been described and analyzed as well (e.g., Anderson 1990; Sharkey 2006). Stressing two points of street wisdom is important to understand the relationship between it and becoming a victim. First, having knowledge about how things operate on the street is helpful for daily routines, but it does not provide protection in unexpected situations, like police controls. Second, to build a reputation, violence is embedded in this knowledge, as has been described in the interviews as well as by Anderson. Thus, the paradox of street wisdom is that it helps young street-involved youth to stay out of trouble, as well as justifying violence, when these specific norms on the street are breached. It becomes necessary to act violently to defend one's own reputation, but not to build it up. However, the causes of aggression and "defense" are not always a physical act; mere "wrong" eye contact or answers to questions can be triggers. In extreme cases, like gang membership, street wisdom guarantees coming into violent situations (Dierenfeldt 2017; Stewart et al. 2008).

In sum, the core assumptions of the street code approach are stable across all contexts. Respect, neighborhood perception as well as street wisdom are powerful elements of a broader street code concept to explain youth violence in risky neighborhoods, independent of the cultural framework. However, other elements of the code of the street differ from the findings of Anderson and an analysis cannot stop at the verification of important aspects; the differences too need to be considered to

\footnotetext{
${ }^{1}$ Interestingly, we can show in a new study, which is based on other data sets, that even non-violent participants of street culture engage in the same attitudes and behaviors in Germany; they just avoid violence. Due to their outfits, habitus, and especially their aggressive appearance, they are not easy to distinguish at first glance from violent individuals. It is noteworthy that they do not merely imitate violent participants in some kind of fake mode of street culture in order to appear as something that they are not; it is merely their way of living and interpreting street culture. Moreover, the non-violent participants are usually the majority of youths in such neighborhoods (Zdun 2019). This even adds to the argument that respect and recognition might be more relevant in street culture than violence; at least in certain locations.
} 
develop the street code approach as a framework to explain youth violence in risky neighborhoods independent of the cultural framework.

\subsection{Differences to the Code: Evidence of Cross-Cultural Comparison}

In Chap. 3, research of the code of the street was deconstructed down to its core elements. Besides the three elements discussed above, which are the core of the concept, five more turned up. In all of them, the findings vary between the proposition of the street code approach, worked out in the US context, and our findings. For some elements, we found results which would verify the assumption of the street code approach, but not in all contexts. This gives us a hint that major parts of the code of the street are influenced by the cultural framework within which it is embedded.

The first of these elements is the social construction of an enemy. As discussed in Chap. 9, an enemy is more a threat to social reputation by deviousness or gossip, and not an opponent in a fight, with the clear exception of the South African context. However, in the US context, as described in the study about Germantown, as well as in the South African context, high levels of violence are part of daily life because of an absence of community regulation on the street. So, if the environment itself is threatened directly by violence, enemies are not respected, neither in a fight nor as a person. This interpretation hints to a tipping point regarding the level of violence in the neighborhood and the strategy required to treat an enemy. Our data point out that the Germantown neighborhood in Philadelphia in the early 1990s was quite violent, which provoked physical violence towards an enemy, but that is not the general rule of how to act in a risky neighborhood. The patterns are more complex and the consideration between violence as a way to react on a provocation, the norms of the family, behavior of friends and spatial circumstances, like the local street culture, form the relationship between two enemies.

The second element, where the findings were different to what was assumed, is toughness. Reassured by a sample of exclusively male juveniles, the findings of the element are close to ideas about masculinity. However, toughness is not proximate to violent behavior or respect in the street way, as proposed by the findings from the Germantown neighborhood. For example, a number of the very young in our sample were described as a symbol of masculinity and toughness, which guaranteed respect among peers, but none fitted the description of behaving as an "old head" or "decent daddy, who takes care about them" (Anderson 1999: 180). Probably because of the absence of the dichotomous logic of "street" and "decent" families in our three contexts and ten neighborhoods, this type of father image was not reported. As Anderson cleared up, such behavior is typical for those he classifies as "street". However, other research shows that such a typology does not work outside of the US or in extreme circumstances, like homeless children (Naterer 2015) or prisons (Mitchell et al. 2017). Constant in our findings is the idea that social mobility is a sign 
of toughness and also masculinity. Despite the notion that the ability to fight when needed is linked to toughness and masculinity, the ideal to build up a good life for himself and his future family, by finishing school and having a legal job prevailed. This is also true for the older boys in the sample, who fall into the extreme of the parameter of the sample's age cohort and were already working. In the German case, close to all respondents share the desire to live in a house with a garden with a wife and children in the suburbs one day, which is the classic middle-class image.

Also, the perception of symbols varies between our findings and those of Anderson. The link between violence and the symbolic world is by far not so close as we thought, based on the street code approach. Brand clothes, for example, were not highly desired by the juveniles in our sample from their point of view. Furthermore, Pakistani juveniles claim that the traditional clothes are valuable as well, even in the risky neighborhoods of a metropolitan area and these neighborhoods have a higher population density than that of Philadelphia in the 1990s. The argument that the element of the street code is true only in "western countries" is contradicted by the findings from Germany, were brand clothes or expensive cars are not seen as necessary or something to rate highly. Among the juveniles, social values were more important, like being a good friend, who to respect, etc. However, it does not mean that symbols of wealth are not important, but they are not connected to respect or violence directly, more as a flag of status, which is in line with some of the descriptions of the Germantown neighborhood in Philadelphia. But neither in Germany nor in South Africa or Pakistan are symbols or a clear sign of a way of life in risky neighborhoods evident. So, the element of symbols is culturally framed, and this is not surprising. Symbols carry knowledge with them, which reflect parts of the circumstances of life in the context in which it is developed. What Anderson describes is an American perspective on symbols in risky neighborhoods, which do not have the same meaning and function in other parts of the world. However, symbols are more an element of a street code, which explains violence; it is a part of the micro-level street culture as a whole and shows belonging to a neighborhood with its norm shared by a part of the residents.

The fourth element of the street code where we found dissimilarities, is the element of friends, their role and perceptions thereof. In the original work, friends are a source of power and usually part of street life and engaged in the drug market or with the will to do so. We do not question that deviant peers could have an influence on others to become criminal as well Thornberry et al. (1994), but their role is much more complex than claimed. For example, the data from Pakistan shows that cousins are friends as well, which is true for some Arabic-German juveniles as well. Here the concept of friends overlaps with family issues, which means that the norms of the family operate in the friend groups as well. Often, those families held up traditional roles and religious duties. Hence, the role of the friends in the development of a street code is limited under such circumstances, even if the poverty rate and blocked opportunities in life are higher than in the US context. Furthermore, in all three countries in which we did research, friends were perceived as sources of emotional support and people to spend time with, which also means that comparison among friends does not dominate daily life. An exception is when it comes to contact with 
Table 11.1 Comparison of homicide rates, per 100.000 inhabitants

\begin{tabular}{l|l}
\hline Country & Homicide Rate (2016) \\
\hline Germany & 1.2 \\
\hline Pakistan & 4.4 \\
\hline South Africa & 34.0 \\
\hline USA & 5.4 \\
\hline
\end{tabular}

Source http://www.unodc.org; last viewed: 06th October 2018

girls of the same age. Here the role of friends is two-faced. On the one hand, they are perceived as an important part of life, on the other hand, they are potential enemies, by way of trickery, gossip or taking someone's girlfriend. This ambivalent role of friends is the reason why the interviewed juveniles make a distinction between friends and close or real friends.

The fifth important dissimilarity is the perception and interpretation of violence itself, and this differs not only between our findings and those of Anderson, but also between the contexts analyzed. In the South African context, violence is a symbolic currency by itself. It makes sure that things keep running or have been done. Logically, the level of daily violence is much higher than in the other two contexts or that of the Philadelphian Germantown neighborhood in the 1990s. The Pakistani case is ambivalent, regarding the perception of violence; we observe in some interviews the same as in South Africa, but also a clear rejection of violence as normal behavior. In the German context, we observe a wide disagreement among male juveniles regarding violent acts, even if they "need" to do it sometimes. This begs the question as to how these differences can be understood. Noticeable is that the differences are seen at the country level, and this hints at macro-level impact. The pattern described correlates with the level of the homicide rate, as seen in Table 11.1.

Risky neighborhoods are specific contexts, but not independent of the city, metropolitan area or nation as a whole. This means that the macro-level of violence frames the interpretation of such on the local level as well and this is what we found in the comparisons of the data of our study, but also with the findings of Anderson. The result is that all are correct in the context of their national or relational position. However, violence has a very different character in street culture and its norms, depending on the level of violence of the entire society. The way it is used and interpreted on the street and among male juveniles is not static and more an outcome than an element by itself.

In a nutshell, the level of violence in street culture is much higher in societies/communities with an overall high level of violence, such as South Africa, particularly, but also certain neighborhoods in the US. We have already demonstrated this difference in a cross-cultural comparison of Brazil, Germany, and Russia (Zdun 2008). While violence has an existential character in the street culture of some countries and is about a daily struggle for survival, it has a more light-hearted character in other locations, where it is often just a competition for respect and recognition 
but does not include fights for territories and illegal businesses. ${ }^{2}$ Thus, engagement in violence and the extent of violence should be seen as a spectrum, ranging from rather low in countries such as Germany to regularly lethal in countries such as South Africa.

\subsection{What Does it Mean for the Code of the Street as a General Approach?}

The wide discussion about the original claim of the code of the street with its advantages and limitations highlights two thoughts. On the one hand, the code of the street is a powerful concept through which to understand youth violence in risky neighborhoods, but, and this is the second point, more so in the US context than in others. We have to notice that most of the published research about the code, as well as its basic study, was conducted in the US or with US data. There, the findings are clear and there is no doubt that such a street code is developed in risky neighborhood, especially if they are predominated by African Americans. Otherwise, the extensive use of the FACHS data, which includes only African American families in Georgia and Iowa, in studies about the code of the street cannot be explained. Even previous studies about the code of the street conducted in the US rarely ask for the code in Latino neighborhoods (Rojas-Gaona 2016) ${ }^{3}$ or in smaller towns (Keith and Griffiths 2014).

But the restriction of an explanation of the code of the street for youth violence in risky neighborhoods is a starting point to develop this fruitful concept into a real general approach. Therefore, our findings in very different countries are helpful. Anderson is right when he claims that elements of the code are stable, independent of space and time (Anderson 1999: 179), but it is not true for the entire concept of the code. The concept of the code claims that a specific set of norms is developed by male juveniles in poor and criminal neighborhoods, which justify violence. This set has several dimensions, but at the core stands respect. In the comparison we have made, the perception of violence, respect, as well as street wisdom, are equal to those of Anderson's study, but all the other dimensions differ, and the reason is twofold.

First, a bottom-up explanation, focuses on the individual. Generally, people, irrespective of whether they live in a risky, mixed or wealthy neighborhood like to be in balance, in harmony, with their environment. So, they develop strategies to fall in with the environment as best as they can. However, in some neighborhoods, people are threatened by violence, drugs and or in general, deviant behavior. Here, specific

\footnotetext{
${ }^{2}$ But note, street culture violence is also no harmless game in countries such as Germany and might cause severe injuries and even death at times. When a fight starts it can become as hard as it gets in every location. The level of violence and the readiness to kill are just different in an overall framework.

${ }^{3}$ For sure, the group of Latinos has been described in criminological further studies, which do not use the street code approach explicitly. (e.g. Bourgois 2003; Martinez 2004; Burchfield and Silver 2013)
} 
strategies need to be developed to be able to cope with the challenges of the environment. If a strategy is acquired and no alternatives are available, for example, role models or caring parents, such strategies are internalized and no longer questioned. Anderson calls the first type 'decent', and those are able to do "code switching". The last type, 'street', are adopted by those who have internalized the coping strategy and its norms as being what is 'right'. Therefore, developing a code is a rational strategy to handle the perceived challenges of a risky environment. Empirical support comes from the finding, which is in line with the original work, of the perception of the neighborhood as a threat. However, the shape of a street code, as a coping strategy, differs significantly between countries and maybe groups. The achievement of the original work is to put the stable elements of the code into focus, but what is called the code of the street has its limitations and is applicable in its entirety to only a few neighborhoods in the world.

The top-down explanation refers to the other elements of the code. Here, macrolevel influences, like the general level of violence and crime in a society (Kesteren et al. 2014), a history of discrimination (Maylam 2017), or the type of welfare state (Esping-Andersen 1990) form the elements of the code in a significant way. The role of friends or the perception of violence are examples of this. So too are how the police are perceived or the role of symbols on the street. In this regard, the code, which was described in the Germantown neighborhood of the 1990s, is a very specific one, shaped by the context of African Americans in a risky neighborhood. Certainly, the social mechanism, as a reaction to a challenging environment, is true, but the face of the code, meaning the coping strategies and with them a set of norms, differ according to context. Following this argument, one can state that Anderson found the (African) American Code of the street, but not a global phenomenon.

The empirical findings of our international research project show that historical, economical, but also cultural circumstances influence the form of street codes in significant ways. With Anderson's seminal work in mind, only a few of the elements are stable across all contexts, but the differences are more important, which is true not only for the comparison between our three cases but also regarding the theoretical approach toward the code of the street. Coming back to the macro-driven factors that form the code, three factors need to be considered to understand the construction of sets of violence-related norms in risky neighborhoods:

(1) The different opportunity structures to integrate young people into the functional systems of society, for example, education, labor or housing. These are sources of recognition and pathways to social mobility. Obviously, these functional systems of society are confronted with social inequality within, but also between countries. Cross-cultural comparisons show that social inequalities undermine the social cohesion of a society, and consequently violence increases (Wilkinson and Pickett 2009). Thus, the street becomes a staging area too for male juveniles to campaign for their recognition, or as they say, respect. However, respect is not a social recognition, more a peer-driven factor, especially if respect requires violence. Important to note is that nobody can live without recognition, but 
violence is not a mechanism to gain respect or recognition in the overall context, as our analysis has shown.

(2) Bound up with this is the development status of a society. Here of significance is where we did our research. Signs of this factor are the different standards of the welfare system and the level of segregation. These macro-driven circumstances determine the need to develop a street code. In the townships of Cape Town, a street code needs to guarantee the ability to survive in one of the most dangerous parts of the world, while in Berlin the street code has to be practical to cope with a challenging, but not life-threatening environment.

(3) A street code can only be understood by taking the normative structure of the wider society into account. It is formed in opposition to the circumstances in the entire city or society but is not a globally shared norm. What is normal in the US can be strange in Pakistan. Thus, we cannot assume a global street code, but a code which is formed by the culturally specific circumstances of society.

Therefore, the code has its culturally-specific face and the characteristics of important elements differ and someone who grew up in a risky neighborhood in Pakistan cannot utilize the Pakistani street code to get by in a risky neighborhood in South Africa. However, to analyze and compare street codes, the concept of Anderson, with its element, is very useful. The core of the code, respect, but also the perception of the neighborhood and informal rules on the street help to understand the basic dynamics in a given neighborhood. The other elements of the code cluster around this core and is questionable if the list of elements - enemy, symbols, friends and toughness - is exhausted. We found evidence for the need to take into account the factors of success, the role of the family, new technologies, as well as perception of the police. But for all findings, the range of explanations require reflection. Such an approach is analytically helpful to understand, for example, youth violence in Indonesia, but the findings are not generalizable on their own. It is more that $a$ code is operating, not the code, and is has to be viewed in the cultural context where it occurs.

To understand the street codes and the mechanism which shape them, it is helpful to incorporate them into the broader discussion about street culture, which can be understand as a set of norm-based activities of individuals or groups in public or semi-public spaces with specific purposes and mechanisms of recognition and a shared interpretation of symbols. Such activities provide a hyper-local social status among peers and neighbors as well as the impression of the ability to stay out of street violence, if needed. The behavior of juveniles, police officers, taxi drivers or even drug dealers are a part of it and form the world individuals perceive and interpret. By doing so, the development of a street code, to navigate environmentally driven challenges, is logical, and is a negotiation with the broader spectrum in which people are embedded. This would also close the gap between the street code concept on the micro-level- and the macro-level characteristics, like the homicide rate. From an analytical perspective, street culture stands between these dimensions by bringing more than just one group into focus but is reconcilable at the local level. 
With all this in mind, the discussion about the code of the street, more specifically its applications and limitations, as we have elaborated in this study, show the need to develop the code into a real general approach. Therefore, it is necessary to keep in mind what the stable elements are and what is formed by macro-level influences. Furthermore, analyzing street codes as characteristics of street culture helps to understand the challenges and circumstances under which street codes are developed. Beside further cross-cultural comparison studies, which we really need, it is necessary to steer toward the street codes of the other users of the same space than "only" that of juveniles so as to bring together the different coping strategies of street codes of a risky neighborhood. This would open the perspective to different normative worlds within a space and opens the path to understand what stands beyond violence on the street.

\section{References}

Anderson, E. (1990). Street wise. Race, class and change in an urban community. Chicago/ London: University of Chicago Press.

Bourgois, P. I. (2003). In search of respect: Selling crack in El Barrio. Cambridge: Cambridge University Press.

Burchfield, K. B., \& Silver, E. (2013). Collective efficacy and crime in Los Angeles neighborhoods: Implications for the Latino paradox. Sociological Inquiry, 83(1), 154-176.

Dierenfeldt, R. et al. (2017). Street culture and gun violence: Exploring the reputation-victimization paradox. Journal of Interpersonal Violence, 1-27.

Esping-Andersen, G. (1990). The three worlds of welfare capitalism. Cambridge: Polity Press.

Keith, S., \& Griffiths, E. (2014). Urban code or urban legend: Endorsement of the street code among delinquent youth in urban, suburban, and rural Georgia. Race and Justice, 4(3), 270-298.

Kesteren, J. V., Dijk, J. V., \& Mayhew, P. (2014). The international crime victims surveys: A retrospective. International Review of Victimology, 20(1), 49-69.

Martinez, R., Jr. (2004). Latino homicide. immigration, violence, and community. New York: Routledge.

Maylam, P. (2017). South Africa's racial past: The history and historiography of racism, segregation, and apartheid. New York: Routledge.

Mitchell, M. M., Fahmy, C., Pyrooz, D. C., \& Decker, S. H. (2017). Criminal crews, codes, and contexts: Differences and similarities across the code of the street, convict code, street gangs, and prison gangs. Deviant Behavior, 38(10), 1197-1222.

Naterer, A. (2015). Violence and the code of the street: A study of social dynamics among street children in Makeevka, East Ukraine. Journal of Interpersonal Violence, 30(8), 1387-1402.

Rojas-Gaona, C. E. (2016). Adoption of street code attitudes among Latinos and its effects on criminal offending. Doctoral dissertation, University of Cincinnati

Ross, J. I. (2018). Reframing urban street culture: Towards a dynamic and heuristic process model. City, Culture and Society, 15, 1-7.

Sharkey, P. T. (2006). Navigating dangerous streets: The sources and consequences of street efficacy. American Sociological Review, 71(5), 826-846.

Stewart, E. A., Schreck, C. J., \& Brunson, R. K. (2008). Lessons of the street code: Policy implications for reducing violent victimization among disadvantaged citizens. Journal of Contemporary Criminal Justice, 24(2), 137-147. 
Thornberry, T. P., Lizotte, A. J., Krohn, M. D., Farnworth, M., \& Jang, S. J. (1994). Delinquent peers, beliefs, and delinquent behavior: A longitudinal test of interactional theory. Criminology, 32(1), 47-83.

Wilkinson, R. G., \& Pickett, K. E. (2009). Income inequality and social dysfunction. Annual Review of Sociology, 35, 493-511.

Zdun, S. (2008). Violence in the street culture-the relevance of the male ethos and crime. New Directions for Youth Development, 119, 39-54.

Zdun, S. (2019). The fluid nature of street culture: Participation in street culture as an adaption through the life course. In J. Ross (Ed.), Handbook on street culture. Routledge (in work).

Open Access This chapter is licensed under the terms of the Creative Commons Attribution 4.0 International License (http://creativecommons.org/licenses/by/4.0/), which permits use, sharing, adaptation, distribution and reproduction in any medium or format, as long as you give appropriate credit to the original author(s) and the source, provide a link to the Creative Commons license and indicate if changes were made.

The images or other third party material in this chapter are included in the chapter's Creative Commons license, unless indicated otherwise in a credit line to the material. If material is not included in the chapter's Creative Commons license and your intended use is not permitted by statutory regulation or exceeds the permitted use, you will need to obtain permission directly from the copyright holder. 